\title{
An Investigation into Restaurant Attributes: A Basis for a Typology
}

Pedro Longart, Eugenia Wickens \& Ali Bakir

To cite this article

Pedro Longart, Eugenia Wickens \& Ali Bakir (2017): An Investigation into

Restaurant Attributes: A Basis for a Typology, International Journal of Hospitality

\& Tourism Administration, DOI: 10.1080/15256480.2017.1305314

To link to this article: http://dx.doi.org/10.1080/15256480.2017.1305314 


\title{
An Investigation into Restaurant Attributes: A Basis for a Typology
}

\author{
Pedro Longart ${ }^{\mathrm{a}}$, Eugenia Wickens ${ }^{\mathrm{b}}$, and Ali Bakir $\mathrm{c}$ \\ aSchool of Hospitality and Tourism, Universidad de las Americas, Quito, Ecuador; \\ bCollege of Law, Government and International Studies, Universiti Utara Malaysia, \\ Kedah, Malaysia; \\ cSchool of Management and Professional Studies, Bucks New University, High \\ Wycombe, United Kingdom
}

\begin{abstract}
This article has the aim of presenting the basis for a new, clearer classification of restaurant attributes. The research followed an interpretive approach with a systematic review of the literature, compared and contrasted with the findings of six focus group interviews. A new model was devised with seven categories of restaurant attributes. This article presents a model that needs to be tested. Also, follow-up articles with more detail about the attributes under each category will be presented. This article organizes the disparate literature on restaurant attributes and looks into the relationship between attributes, particularly its influence on perceived consumer value.
\end{abstract}

Keywords: Consumer decision making, restaurant attributes, restaurant consumers, restaurant marketing, restaurants

\section{Introduction}

Restaurant consumers base their decision for eating out on the type of experience that is sought (Cousins, Foskett, \& Gillespie, 2002; Jensen \& Hansen, 2007). Macht, Meininger, and Roth (2005) found that the pleasures of eating out are shaped, in addition to features of the environment, by social factors and emotions. Consumers evaluate the components of a service separately, namely service attributes (Bolton \& Drew, 1991). Several attempts have been made to establish what these aspects are within the restaurant setting. Campbell-Smith (1967) developed the concept of the meal experience with five different components, which was later refined by Cousins et al. (2002). These components are: food and drink, level of service, cleanliness/ hygiene, value for money, and ambiance. The model has had a considerable effect on education in the hospitality industry and also that it has initiated the application of practical marketing concepts in that industry.

The concept of the meal experience has been subject to criticism. It has been argued that the notion of a holistic experience when eating out should be revised. Morgan, Watson, and Hemmington (2008) disapproved of the possibility of a management-controlled meal experience and proposed that the experience has to be co-created by consumers. A number of alternative methods worthy of consideration have been developed. For instance, Gustaffson, Oström, Mossberg, and Johansson (2006) proposed the five aspects meal model (FAMM) focusing on the operational aspects of the food service. The FAMM model consisted of: the room where the meal will take place (room), where the consumer meets waiters and other consumers (meeting), and where dishes and drinks (products) are served. Backstage there are several rules, laws and economic and management resources (management control system) that are needed to make the meal possible and make the experience an entirety as a meal entirety-expressing an atmosphere. Anderson and Mossberg (2004) also approached eating out as a multidimensional experience and assess the relative importance of six aspects of the dining experience: food, service, fine cuisine, restaurant interior, good company, and other 
customers. They approach eating out as a pursuit for needs. For them, an important difference between dining and lunch customers was found with social needs being important for customers in the evening and more basic physiological needs being important for lunchtime customers. It is important to highlight that the sample of dinner customers was particularly small (55 respondents), compared to lunch customers $(N=255)$. The notion of having fine cuisine as a separate category from food seems confusing as customers may perceive fine cuisine as synonymous with quality of food.

Hanefors and Mossberg (2003) distinguished factors of the meal experience as evaluated by consumers before, during the experience and after the meal. These factors are motivation and expectation (before), interaction and involvement (during), and satisfaction (afterwards). Concerning motivation, the salient factors are "de-routinization," meaning to break away from the normal routine of consumption (something consumers are too familiar with) and pursuit of escape (e.g., from house chores or problems). According to this line of thought consumers expect: no script (contrary to a fast-food experience, for instance), curiosity (evidenced by a menu the consumer has not seen before), and capacity to act (in which the consumer feels freedom to customize their meal or experience-a degree of flexibility).

A study of à la carte restaurants using focus group interviews to ascertain the factors of the meal experience was conducted by Hansen, Jensen, and Gustaffson (2005). These factors are: restaurant interior, the company, and the restaurant atmosphere. They viewed the restaurant atmosphere as an individual's emotional response to the entire experience with the social interactions and feelings of comfort and intimacy. More recently, Harrington, Ottenbacher, Staggs, and Allen-Powell (2011) differentiated between key attributes for positive and for negative experiences in consumers. A total of 29 attributes were compiled. They found that key positive experience drivers (quality of food/drink, quality of service, friendliness of staff, atmosphere of the restaurant, speed of service) were different from the key negative drivers (quality of service, speed of service, quality of food/ drink, friendliness of staff, cleanliness of the restaurant).

The above and other models (e.g., Law, To, \& Goh, 2008) of the meal experience attempt to offer an explanation of those factors which consumers may evaluate prior to making the decision to choose a particular restaurant. Ponnam and Balaji (2014) presented an evaluation of 19 studies from 1997 to 2012 in different contexts and studied attributes in relation to occasions for visiting the restaurant. However, these articles did not offer a classification of attributes. This article presents a review of the literature regarding restaurant attributes and contrasts it with the perception of consumers about restaurant attributes that are relevant to their decision of selecting a restaurant. Since the classification of restaurants vary according to various systems, it was considered to focus on restaurants selected for the purpose of leisure which can be classed as upscale or casual (or casual upscale) dining, considering Barrows and Vieira's (2013) classification. Although it is agreed that expectations for casual and fine dining are different as stated by Hwang and Ok (2013), the purpose of this research is a study of attributes of restaurant in which consumers would arguably spend more time and effort for selecting a restaurant. In support of the choice of this type of restaurants, Dutta, Parsa, Parsa, and Bujisic (2014) found that with regard to willingness to pay, results were similar for both type of restaurants. Studies like the one of Jung, Sydnor, Lee, and Almanza (2015) focus on a narrow range of restaurants and a few categories of attributes. The study acknowledged this limitation, and argues that other attributes should be considered in a wider range of contexts. In this line of thought, this article responds to the need of providing a more organized framework for classifying restaurant attributes, by contrasting actual studies with fresh research on consumers. This research appears to be imperative as many studies of attributes focus on satisfaction with them rather than on evaluation prior to restaurant 
selection. The aim is to lay the foundations for a new typology of restaurant attributes for casual and fine dining restaurants.

\section{Literature Review Introduction}

Several authors have compiled lists of attributes. Some are based on a few studies like Marković, Raspor, and Šegarić (2010), who based their study of 35 attributes on only two articles. An analysis of the different constructs that represent the different types of restaurant attributes can be seen in Tables 1 and 2. Table 1 refers to tangible or mostly tangible attributes. Table 2 refers to intangible or mostly intangible attribute and attributes related to price. Although the study refers mostly to upscale and casual dining, some studies refer to quick service restaurants because obviously some attributes (i.e., cleanliness/hygiene) are common to all types of restaurants. Most of the studies, however, are based on upscale and casual dining.

Studies show that food, atmosphere, and service are three major components of the restaurant experience (Dulen, 1999; Ribeiro-Soriano, 2002; Ryu, Lee, \& Kim, 2012; Susskind \& Chan, 2000). The four main attributes_-food, service, cost, and place (a combination of ambiance, location, facilities such as car parking, and cleanliness/hygiene- - have been investigated by Ribeiro-Soriano (2002). A measurement model by Kim, Lee, and Yoo (2006) used the following classification for attribute dimensions: physical environment, customer orientation (service), communication, relationship benefits, price fairness, and relationship quality. Narine and Badrine (2007) found similar aspects of the meal experience. In the study, food choices were influenced by health/nutritional benefits, safety/sanitation and price of menu. Harrington, Ottenbacher, and Way (2010) supported other studies that indicate the general importance of the following restaurant attributes: (a) food safety, (b) cleanliness, (c) food quality, (d) speed of service, (e) perceived value of the food and drink items, (f) quality of service, (g) staff friendliness, (h) price, (i) variety of menu, and (j) close travel distance. On the other hand, in a study of online customer reviews on restaurants (from the United Kingdom, United States, India, Germany, Italy, Norway, the Netherlands, Sweden, Switzerland, and Spain), Pantelidis (2010) found that the most mentioned factors for customer satisfaction were food, service, ambiance, price, menu, and design/decor. An aspect worthy of investigation is the combined effect of restaurant attributes. So far, only Wall and Berry (2007) have addressed this topic in a study of the combined effects of the physical environment and employee behavior and found that the human element was significantly more important, as to an extent these "humanistic clues" can make up for deficiencies in what they call "mechanistic clues.” Andaleeb and Conway (2006) suggested that to satisfy customer expectations, restaurateurs ought to focus their efforts on service quality, price, and food quality, in that order. Nonetheless, these authors acknowledged that this order is partly induced by the design of their methodology, which is heavily focused on service quality. Gupta, McLaughlin, and Gomez (2007) conducted a study that gathered a set of data regarding factors that most affected customer satisfaction from three hundred (300) outlets of a known restaurant company in the United States and found that the order of significance to the consumer is food quality, price, greeting, and service. In another study, Namkung and Jang (2008) also ranked food first, followed by the physical environment and service. However, their study omitted any consideration to price. And in particular case of fine dining, Arora and Singer (2006) found that food and service are the most influential attributes for repeat business.

From the above, it can be noted that the number of studies about restaurant attributes is overwhelming. For the constraints of space referred to previously, only an excerpt of the most influential—and/or cited—work regarding restaurant attributes is discussed next. 


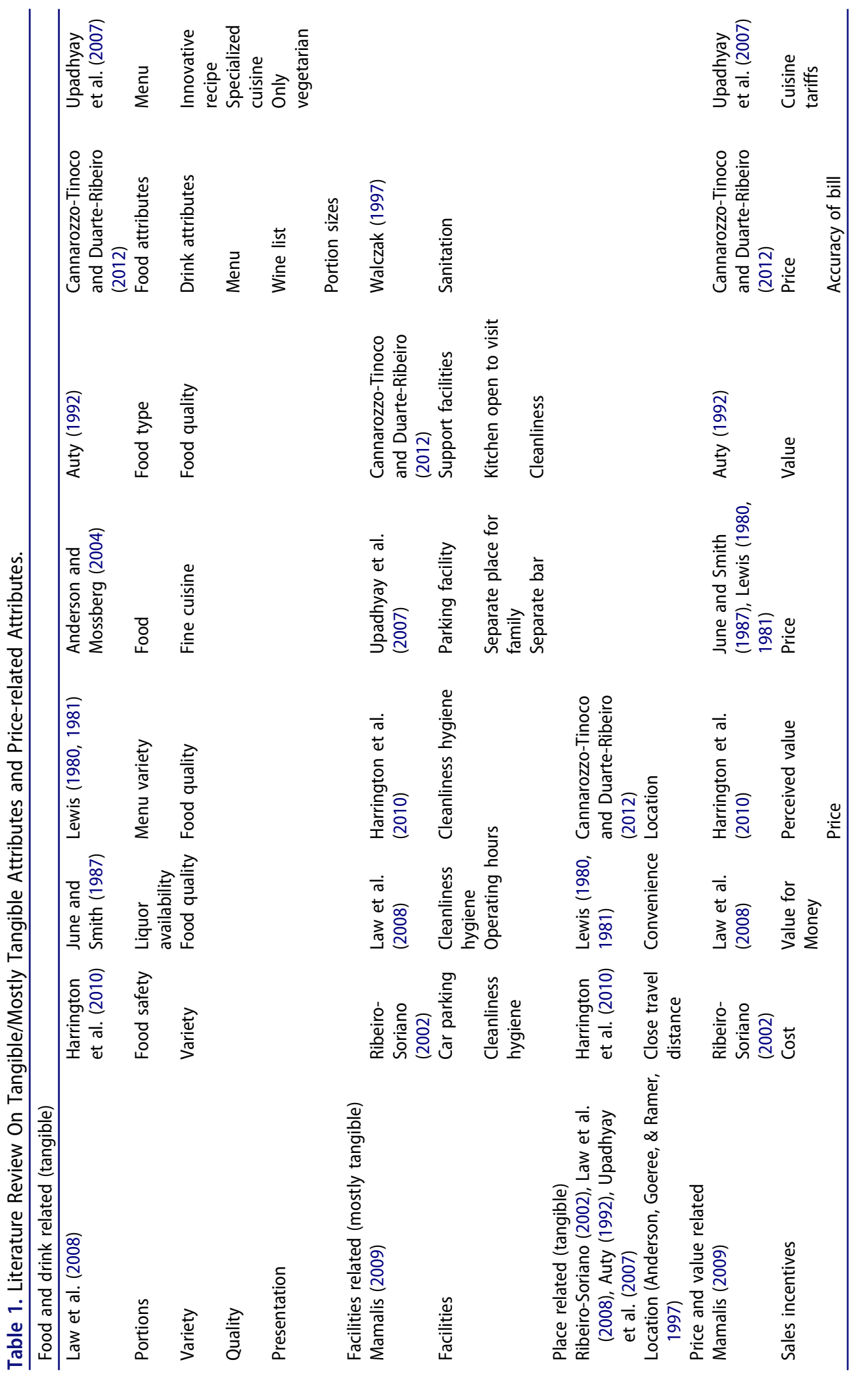




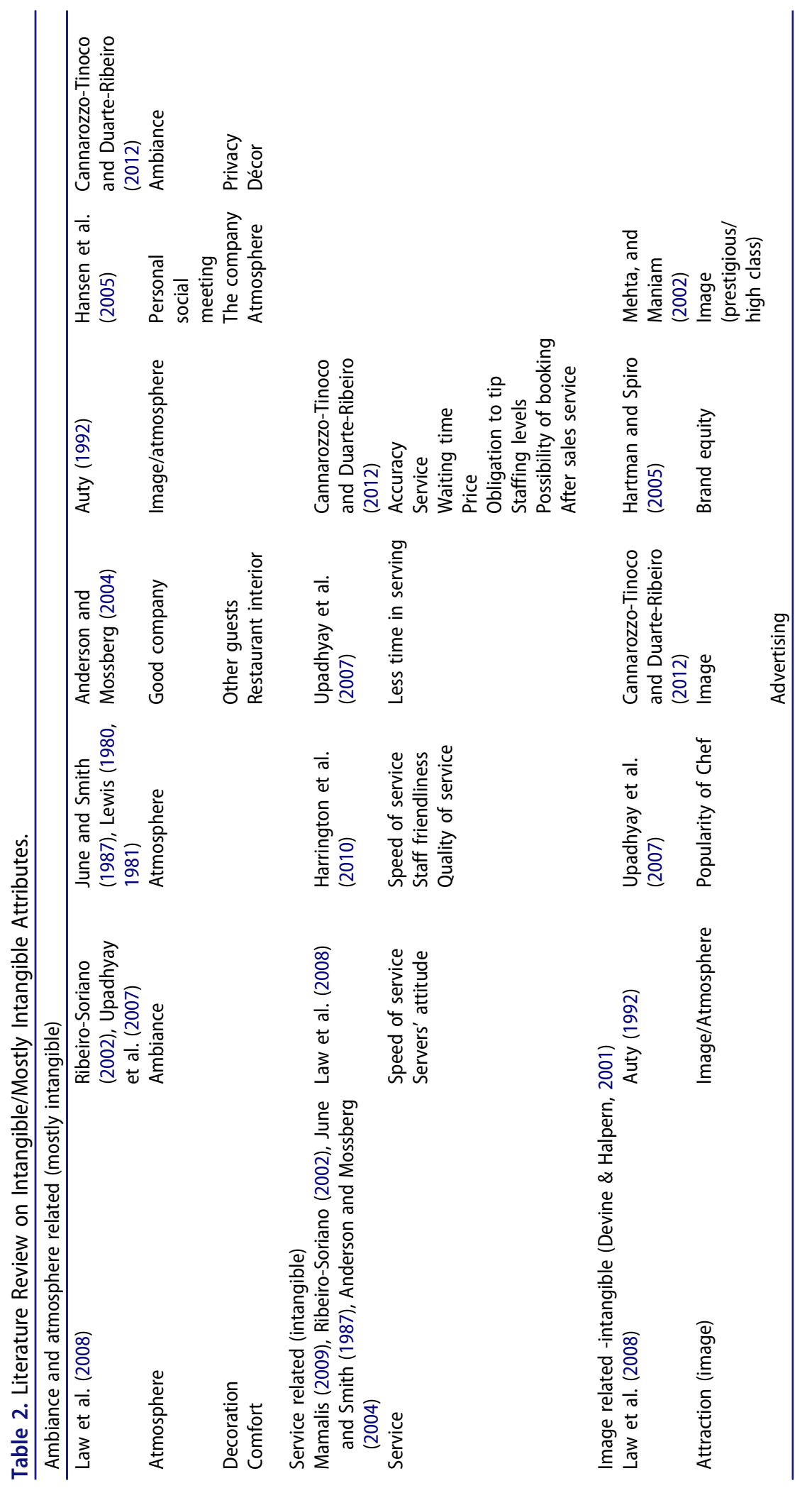




\section{Past Research on Restaurant Attributes}

June and Smith (1987) used other factors to break down the meal experience: liquor availability, service, food quality, atmosphere, and price. June and Smith found that those factors are dependent upon the occasion for eating out. Clark and Wood (1998) commented the low ranking established for quality of food in June and Smith's study may suggest that results were based on a small sample of wealthy consumers. Also ranking importance by customer segment, Lewis $(1980,1981)$ considered five elements: food quality, menu variety, price, atmosphere and convenience. He classifies the order of importance of these factors based upon the market segment to which the consumers belong.

Auty's study (1992) found that the most frequently cited priorities for eating out are food quality and food type. Auty's work was conducted on a cross-sectional representation of three demographic market segments and evoked three types of contexts, albeit less clear in terms of occasion than June and Smith's classification of occasions. Cousins et al. (2002) argued that a better understanding of customers' expectations or the nature of customer demand will help the restaurant operation to develop a product that meets those expectations or that type of demand. They suggested that in the absence of appropriate market research, restaurateurs should establish priorities, depending on the core concept offered.

It is also important to note that relative importance of factors may vary according to the local environment and socio-cultural factors. To illustrate this point, Upadhyay, Singh, and Thomas (2007) conducted a study of restaurant attributes for consumers dining out in India, and found the following attributes (in order of importance): quality of food, safety, menu, location, less time in serving, parking facility, ambiance, cuisine tariffs, separate bar, innovative cuisine, specialized cuisine facility, only vegetarian cuisine facility and popularity of chef. These authors have attempted to present a comprehensive list of all factors affecting the decision. However, with a high number of factors, it is very difficult for respondents to rank factors regardless of the methodology employed. Besides, it has the important limitation of not considering a wider range of restaurants, other than fine dining.

It is clear that the number of factors analyzed by different authors vary greatly, but that variety is caused by different approaches, different market segments or different contexts. This richness may influence the different outcomes. This concurs with the comments of Law et al. (2008, p. 347): "In relation to the important attributes for a restaurant selection, the findings of prior studies have not been analogous to each other.” Pantelidis (2010) seemed to agree by concluding that efforts to prioritize expectations or set them in a hierarchy have been inconclusive. And in respect to the variety of restaurant attributes discussed, they all appear to be, to some extent, variations of the meal experience model. Now, what the various elements of the meal experience entail required detail discussion prior to attempting the proposed foundations of a new typology.

\section{Food and Drink}

Food and drink is the most significant of all the aspects of the meal experience. This may be because people forgive poorer service more readily than poor food quality (Denove \& Power, 2006). Pantelidis (2010, p. 488) also confirmed the importance of food and drink as a main trigger for negative comments from customers: "If the restaurant fails to deliver its primary product, the experience will be tainted, and subsequent comments will be negative.” This confirmation has been repeated by several studies that have found that restaurateurs must make food quality its main priority (e.g., Longart, 2010). In this category, unlike other authors, Sulek and Hensley (2004) included food safety and food appeal, although food safety is mentioned marginally (once) in the focus group interviews, this research will focus 
on the second aspect of food appeal, which has elements of food quality.

\section{Ambiance/Atmosphere}

Kotler (1973/1974) pioneered the study of atmosphere in service settings and defined it as "a quality of the surrounding space” (p. 50) that can be described in sensory terms. The dimensions of an atmosphere, he suggested, are visual, aural, and olfactory. The aural dimension has specific studies about the effect of music (Milliman, 1986). In restaurants, as an example, Kotler suggested that restaurants could have a busy atmosphere, a good atmosphere, or a depressing atmosphere. Namkung and Jang (2008) also found that ambiance/atmosphere arouses a number of feelings such as excitement, pleasure, or relaxation. Hwang and Ok (2013) used the term "physical environment" combining both tangible and intangible features and argue that it provides impressions leading to positive emotions like pleasure and arousal in restaurant patrons. These authors found that physical environment quality had a significant effect on hedonic attitudes.

Finkelstein (1989) suggested that ambiance/atmosphere is as important as food and drink in customers' evaluations: "The restaurateur has long accepted atmosphere as a feature of dining out equal in importance and sometimes more important than the food itself” (p. 59). In support of this argument, Babin, Lee, Eun, and Griffin (2005) proposed that an increased emphasis on the physical environment plays a critical role in enhancing positive consumer outcomes. Harrington et al. (2011) also found that restaurant atmosphere, in general, is an important driver of positive experiences amongst young restaurant patrons. To delve into the topic of atmosphere is indeed challenging as it is obviously made up of and affected by numerous factors; some are considerably more controllable than others. The less controllable factors may be part of what Gladwell (2000) called the "power of context."

\section{Value for Money/Perceived Consumer Value}

Marney (2001) argued that customer perceived value is sometimes a better predictor of customer behavior or market outcomes than customer satisfaction. Zeithaml (1988) distinguished extrinsic and intrinsic attributes of either lower level or higher level. Zeithaml found that lower level attributes affect perceived value and perceived quality and that high level attributes affect perceived value only. Teas and Agarwal (2000) found that extrinsic cues such as brand and price affect perceived quality and perceived value. Even though service quality and value are not identical constructs, perceived service value is a richer, more comprehensive measure of a consumer's overall evaluation of a service than service quality. It is a higher construct more individualistic and personal than quality. Consumers make decisions in a means-end way, looking for value. The means are the linkages between attributes that exist in products. These means result in consequences that are provided by the attributes, which then provide value to the consumer according to their personal values. This is called attribute value-theory (Reynolds \& Gutman, 1988; Woodruff, 1997). Sweeney, Soutar, and Johnson (1999) distinguished between technical and functional aspects of the service which affect perceived value for money which is also affected by the perceived product quality and perceived relative price. Ha and Jang (2013) based their research on attributes, consequences, and values in restaurant segments. This is because perception of value varies according to the types of establishment and operation (Cousins et al., 2002). Tse (2001) supported the interrelationship of value, quality, and satisfaction and claims there is a trade-off between price and service quality. Tse's research found that whilst "service is an important factor in restaurant selection; customers are nevertheless unwilling to pay an extra amount for a higher level of service, while other things are being held constant” (p. 15). Nonetheless, in a more recent study in the context of fine dining, Nitiwanakul (2014) found 
that both food and service quality influence customer perceived value.

\section{Service Quality}

Service quality is probably one of the areas that have been most researched, particularly in services marketing. However, there are numerous interpretations of what service quality entails. Stevens, Knutson, and Patton (1995) attempted to link service quality in restaurants with the dimensions of service quality indicated by Parasuraman, Zeithaml, and Berry (1988). These dimensions are reliability, assurance, responsiveness, empathy, and tangibles. Stevens et al. (1995) developed a questionnaire that adapts the SERVQUAL questionnaire of Parasuraman et al. (1988) to the restaurant service. They name that instrument the DINESERVE. Noticeably, many items of service quality overlap with attributes mentioned by other authors. For instance cleanliness of dining areas and toilets are enveloped in this concept of service quality. Other authors referred to quality as mainly the intangibles of service. However, in certain service settings where customers spend very little time (e.g., fastfood restaurants), quality is perceived primarily on the basis of intangible factors. Wakefield and Blodgett (1994) considered two aspects: time spent in the place and purpose of visit (e.g., hedonic vs. utilitarian). Restaurants are labeled as moderate in time spent in the facility, and a combination of utilitarian and hedonic as purpose of visit. Regarding adaptation of service quality instruments to the restaurant context, Namkung and Jang (2008) warned that despite the broad applicability across all for SERVQUAL service sectors, attention should be paid to adapting SERVQUAL to a specific setting.

Pedraja and Yague (2004) linked the perception of price with service quality expected in restaurant settings and found a significant relationship, with higher perception of price and higher service quality expected. Perceived service quality is defined as the difference between customers' expectations and their perception of service delivered. In practical terms, it means that different restaurant operations should match different customers' expectations. This match was represented in a matrix where levels of conviviality (service) and procedure (operation) were tabulated. This seems to imply that fast-food operations are high on procedure and low on conviviality, whereas customers in the context of this research expect high levels of procedure and conviviality. Finkelstein (1989) commented that the regimented nature of the exchange between the customer and serviceperson in McDonald's are structural barriers to civilized society as "formulaic exchanges prevent any recognition of each other as unique” (p. 11).

\section{Cleanliness/Hygiene}

Another aspect mentioned by Cousins et al. (2002) and one of the original components of the Campbell-Smith (1967) model is cleanliness/hygiene. Cousins et al. (2002) explained that this concept is related to staff, premises, and equipment. There seems to be no consensus about the importance of this factor. Barber and Scarcelli (2009) found that consumers are indeed concerned with cleanliness and food safety. In particular, restrooms are found to be an important factor when assessing the cleanliness and hygiene of a restaurant. Cadotte and Turgeon (1988) ranked it as fourth in a list of restaurant attributes. And in a study of restaurant attributes in Malaysia, Josiam, Sohail, and Monteiro (2007) found that cleanliness of toilets and overall cleanliness are the highest ranked factors, almost as important as food quality. In contraposition to these findings, Titz (2004) found that sanitation was a hygiene factor, which meant that it was important only when not present. Thus, it is something expected by customers, but arguably not a factor for choosing a restaurant.

The relative importance of cleanliness/hygiene appears to be very high when the market segment is that of parents looking for a place to have a family meal. This is because parents 
serve as "gate-keepers” who control their child's access to the quality and quantity of foods, and this is particularly true for young children. The aspect of cleanliness/hygiene has been identified as a key attribute related to service quality in fast-food (also called quick-service) restaurants (Harrington et al., 2011). This consideration of cleanliness as critical to the firm's image rather than a peripheral aspect was confirmed in more recent research. Indeed, VilnaiYavetz and Gilboa (2010) found that in full-service restaurants, cleanliness influenced both consumer trust and willingness to patronize the restaurant in the future. Interestingly, they also found that the perceived cleanliness of the serviceperson's dress also influenced positively the amount of tip received.

\section{Location}

The importance of location or mention of it as a restaurant has been listed in this literature review. It is important to note that it is vital to define precisely what is understood by location. In some cases, location is just mentioned by its name without precise definition of what it means to the consumer. To name just one study, Kivela (1997) associates the importance of location to fast-food restaurants; however, what they mean by a good location is not clearly defined. Reference to location varies according to the context of the research which may range from type of restaurant studied, geographical location, tourist destination or cities, etc. Koo, Tao, and Yeung (1999) conducted a conjoint study with location and three levels: Outlying island, urban, or rural. Keyt, Yavas, and Riecken (1994) conducted a study in one restaurant in the United States where consumers rated that restaurant in terms of "convenience of location" and found that it was an attribute of less importance even than portion sizes. Likewise, in an evaluation of factors affecting customer loyalty, Haghighi, Dorosti, Rahnama, and Hoseinpour (2012) found that it did not have an impact on customer satisfaction. In the context of tourists, Yüksel and Yüksel (2003) found that a segment of tourists (atmosphere seekers) was more concerned about a convenient location, which the researchers associated with restaurant appearance. Indeed, restaurateurs consider alternatives before locating a restaurant. In this respect, Tzeng, Teng, Chen, and Opricovic (2002) evaluated the restaurant location process from the perspective of customers and management. With regard to customers, they pointed out that convenience of mass transportation system and parking capacity seem to be more related to the context of the United Kingdom. Location is also an objective attribute used in context-aware restaurant recommendation through mobile devices. Park, Hong, and Cho (2007) devised a mobile application using an expectation maximization algorithm for selecting a restaurant based on aspects such as availability of parking area and distance from the consumer together with attributes like type of restaurant, price level, etc. From the examination of the literature, it seems that a clear definition of location and research on how it affects the decision of selecting a restaurant is in need of investigation.

\section{Restaurant Image}

Interest in image as an aspect worthy of consideration has increased because of its potential influence on an individual's subjective perception and consequent behavior (Castro, Armario, \& Ruiz, 2007; Chen \& Tsai, 2007; Ryu, Heesup, \& Tae-Hee, 2008; Tasci, Gartner, \& Cavusgil, 2007). However, there are conflicting conceptualisations of image. Ryu et al. (2008, p. 460) conducted a study of image for quick-casual restaurants and defined image as a bundle of tangible aspects: "a function of the attributes of quick-casual restaurants that are salient for valuation." They examined brand name as a tangible cue for restaurant image together with décor and interior design and price, and this seems to bundle together both tangible and intangible factors. It seems more sensible to concentrate on brand image as affecting that sum of beliefs that consumers may have. Following this order of ideas, in a later 
study they referred to restaurant image as the sum of the emotional perceptions, ideas, or symbolic attitudes that customers associate with restaurants (Ryu et al., 2012). For other authors, image attributes are made up of aspects of the meal experience that have a considerable impact on customers' loyalty such as service personnel, pricing, ambiance, and overall cleanliness (Dhurup, Mafini, \& Malan, 2013). In this line of thought, Yun and Good (2007) defined image as a complex blend of tangible and intangible elements. However, consumers may attach value to brands beyond their tangible benefits. Akin to the concept of brand image is corporate reputation. Corporate reputation is itself a cue that affects customers' perceptions of a company's product/service quality (Chang, 2013). It significantly affects customer-perceived trust, customer-perceived value, and customer satisfaction. Chang added that since the restaurant industry offers its customers the experience of a product/service, a restaurant's reputation could be a very important consideration for customers when choosing a restaurant. In the particular context of ethnic restaurants, Lu et al. (2015) found that consumers' authenticity perceptions, which arguably can be seen from an angle of image, have significantly positive relationships with brand-related constructs and brand choice intention.

The previous discussion comprises studies that influenced the direction and design of the study of this work. In what follows the article presents the methodological approach adopted in the study

\section{Methodology}

The starting point was a systematic review of the literature. This, in our view, needed to be complemented with qualitative data analysis of focus group interviews so as to find up-todate perceptions of attributes. This is particularly relevant as some studies were conducted quite a few years ago and in several research contexts. These focus groups interviews were conducted in the southeast of the United Kingdom (London and vicinities). This resulted in six semistructured interviews with questions prompted by an interview guide. The respondents were selected under the criteria that they have frequently eaten out restaurants for leisure (as opposed to convenience) and that they have been involved in the decision to select the restaurant. Most of the respondents reported that they are frequent restaurant goers and were indeed involved in the selection of a restaurant. Indeed of the sample, 58\% eat out at least once a month, 36\% at least once a week, and only $6 \%$ eat three to six times a year. This convenience sample was formed by respondents with various occupations, such as professionals, academics, managers, and homemakers, and ages ranging from the mid-20s to the mid-60s. In total, 33 respondents took part, 15 male and 18 female. Each focus group consisted of four to six participants who were requested to talk about how they selected a restaurant, including questions about attributes that they would consider in their selection criteria. The restaurants the respondents selected ranged from casual dining to Michelin-star restaurants but required a minimum level of service (be seated by a serviceperson). Fast-food restaurants were not part of the respondents' deliberations about restaurants.

The focus group interviews took around 45 minutes on average. The interviews were recorded using an iPad. The data was then organized using qualitative data analysis software (QDAS). The software of choice for this purpose was Nvivo because it is increasingly flexible in adapting to the demands of modern research (Bazeley \& Jackson, 2013).

Analysis of the interviews was conducted using applied thematic analysis. The main advantage of applied thematic analysis is that it is a tool that cannot be characterized as a specific method but as a tool to use across different methods (Boyatzis, 1998). Indeed Braun and Clarke (2006) cited a number of advantages, an important one is that besides its flexibility, it allows for social as well as psychological interpretation of the data. 
There are two main categories of themes. The first is the one that Guest, MacQueen, and Namey (2012) labelled as the structural approach, which is defined by Di-Cicco-Bloom and Crabtree (2006) as a template approach as it involves applying a template (categories) based on prior research and theoretical perspectives, which are imposed by the research design. This is the case for many of the questions asked in the interviews in this research as prompts to interviewees to raise restaurant attributes that have been discussed in the literature. The second category is that of emergent themes from the discussions by the interviewees.

The research followed Ritchie et al.’s (2014) framework for analyzing data, starting with familiarization with the data. This process of data management began in the literature review and continued by reviewing the interview transcripts.

Restaurant attributes then went through a process of classification, contrasting the various studies within themselves and with the results of the interviews. First, the attributes from the literature were analyzed and classified into a number of tangible or intangible attributes. Then a process of refinement of data followed. This process of several refinements was described by Dye, Schatz, Rosenberg, and Coleman (2000) using the analogy of a kaleidoscope of data. These attributes were compared with the thematic analysis developed from the focus group and a preliminary list of categories was formed. For example, there are raw data bits that are the different attributes like quality of food and drink mentioned in the literature and in the focus groups. A semantic comparison of terms was conducted to establish similarities. Secondly, sets were formed following the preliminary rule of inclusion, based originally on the meal experience models studied. During the process the rules of inclusion were revised, as some categories seemed to overlap and some data emerging from the interviews appears to shape an existing list of attributes into a distinctive new category. This study of attributes resulted in categories that fit into existing categories and others that did not (therefore a new category was created). After several refinements the final category array was obtained. Then an analysis of links between these categories was conducted as well. The findings pointed to the emergence of a new model of classifying restaurant attributes.

\section{Results and Discussion}

In order to suggest a new typology, the four criteria established by Hair, Anderson, Babin, and Black (2010) were used to support the study's pro- posed model. These are: (a) the interviews appear to establish sufficient relationship between the variables; (b) temporal antecedence of the cause versus the effect (e.g., the award of the Michelin star is achieved before the consumer perceives value from it); (c) theoretical basis for the relationship; and (d) lack of alternative causal variables. The outcome of the empirical findings and an application of the concept of perceived consumer value led to suggesting a model that shows the relationships between attributes and also between attributes and perceived consumer value (Figure 1). It should be noted that the proposed model is only provisional as it is based on a small sample of respondents. A larger sample is needed to test its applicability.

\section{Overview of Findings}

Cleanliness and hygiene started as a category and then was restructured as an aspect of a category rather than a category itself. After an analysis of lists of attributes, it was considered that it was more appropriate to put it under a new category (facilities). Likewise, references to branding, awards and chef reputation were not deemed to fit into any of the categories discussed, so a new category called image was created. Another issue considered was the relationship between categories. In the meal experience model Campbell-Smith (1967), value for money is considered to be an important attribute. The study was also underpinned by the attribute-value theory (Gardial, Clemons, Woodruff, Schumann, \& Burns, 1994; Reynolds \& 
Gutman, 1988; Woodruff, 1997). It delved into respondents' perceptions on the considerations of value for money and established whether considerations of several attributes are underpinned by expectations based on how much they are willing to spend. Therefore, attribute-value theory was applied for analyzing how the categories of attributes are interrelated.

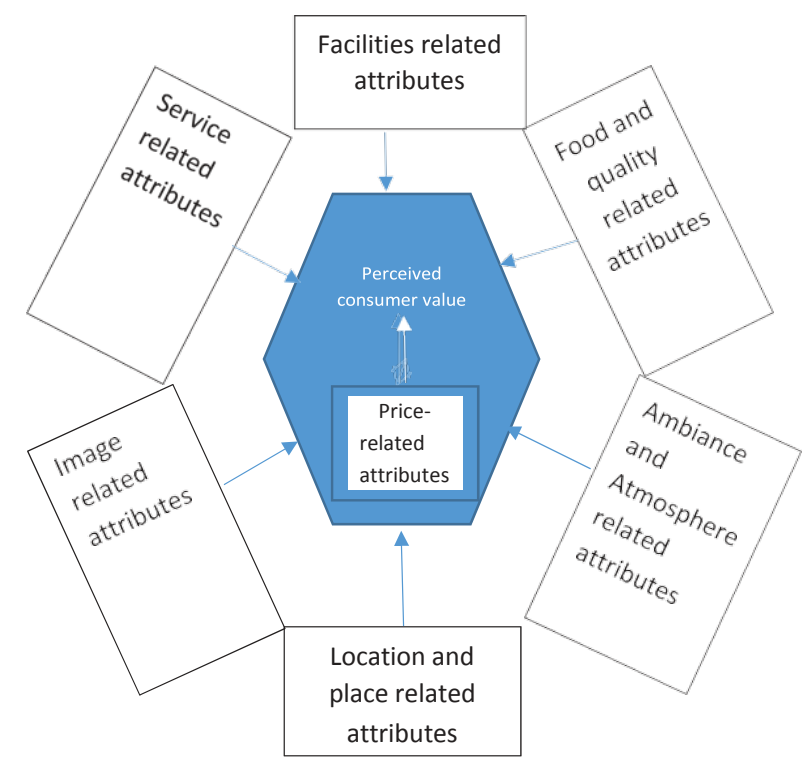

Figure 1. Relationship between restaurant attributes and perceived consumer value.

The study of attributes resulted in categories that fit into existing categories and another that did not (a new category was created). After several refinements the final category array was obtained. Then an analysis of links between these categories was also conducted. Another aspect considered was the relationship between variables, more particularly whether consumer value and price considerations underpin customer expectations and thus evaluation of restaurant attributes are dependent on value appraisals. A new classification of attributes was indicated by the process of comparing categories and the analysis of attribute interrelationships. This appears to be close to Campbell-Smith's (1967) model of meal experience.

Furthermore, Law et al.'s (2008) classification has some similarities with the following attributes and subattributes: food and beverage (portions, variety, quality, presentation), service (operating hours, diversity, speed, and server's attitude), value for money, environment (atmosphere, cleanliness, comfort, location, and decoration), and an additional attribute-attraction (image, novelty, word-of-mouth, advertising).

The cleanliness and hygiene attribute of the meal experience may be included in a new category called facilities. This term is not new as an attribute. It was discussed by Mamalis (2009) but as a restaurant attribute, not as a category of attributes. Other restaurant attributes like driving distance to the place, vicinity to entertainment areas, convenience, and availability of public transport can be linked to the location category (Harrington et al., 2010; Law et al., 2008; Upadhyay et al., 2007). A new category called image was created. Image is highly subjective, relativistic, and dynamic (Gallarza, Saura and Garcia, 2002). This category is slightly different from Law et al. (2008) definition of image as a subattribute of attraction. Four of the original categories of Campbell-Smith were thus kept and three more were added. The final classification of restaurant attributes has the following categories (as shown in Figure 1):

- Food and drink-related attributes; 
- ambiance and atmosphere-related attributes;

- facilities-related attributes;

- service-related attributes;

- location-related attributes;

- image-related attributes; and

- price-related attributes.

\section{Food and Drink-Related Attributes}

This key aspect of the meal experience as mentioned repeatedly in the literature review is referred to sometimes in very loose terms such as food. A more precise term, without attempting a classification, was provided by Cannarozzo-Tinoco and Duarte-Ribeiro (2012): "food and drink attributes." However, quality is considered to be another attribute under the umbrella of food and drink-related attributes. It was deemed necessary to conduct an extensive investigation of what these attributes were, given the multiplicity of references and terms used in the literature. Of all the research conducted on restaurant attributes, quality of drink is only mentioned as one aspect by Cousins et al. (2002) as "quality of food and drink." Also in Cannarozzo- Tinoco and Duarte-Ribeiro (2012), who made reference to this as "drink attributes," and particularly wine characteristics. Curiously, there is just one mention of quality of drinks in the interviews. A respondent stated: "Some of the wines are alright but I'm not fussed about them." Nonetheless, the particular aspect of quality of drink may be worthy of further research.

Some authors refer to range of food and drink variety or availability. In the case of food the attribute, this is termed "menu variety." In terms of specificity for this term, Upadhyay et al. (2007) included vegetarian food as a feature of variety. The inclusion of specials, which was mentioned in the interviews, appears to be a feature of some restaurants. With regard to range of drinks, June and Smith (1987) did not specify variety but the mere availability of drinks (liquor availability). This was also pointed out by the study's respondents as "alcohol availability.” The study suggests that the variety of food and range of drinks should be classed as two different attributes. The food and drink-related attributes and their subattributes are shown in Table 3.

\section{Ambiance and Atmosphere-Related Attributes}

Although food and drink were mentioned by all respondents as particularly important, not all agreed on the relevance of ambiance. Some authors combined ambiance and atmosphere with tangible elements of the place.

However, once the attributes were evaluated, it has been found that whilst some elements of the place or the facilities may influence the ambiance and atmosphere of the restaurant, ambiance/atmosphere appears to be more of an intangible nature. For that reason, a distinction between ambiance and atmosphere (mostly intangible) and facilities-related attributes (a new attribute) is mainly tangible. In the particular case of ambiance and atmosphere the following subattributes have been found: (a) décor and lighting, (b) noise,

(c) music and dancing, and (d) ambiance and atmosphere created by other customers. 
Table 3. Food- and Drink-Related Attributes and Subattributes

\begin{tabular}{ll}
\hline Attributes & Subattributes \\
\hline Quality & Freshness, color, combination of flavors, savoriness, texture \\
Nutritional aspects & Salt and sugar content, salt content, calories content \\
Type of cuisine & Authenticity \\
Variety of food & Specials, vegetarian options \\
Range of drinks & Alcohol availability \\
Food presentation & n.a. \\
Portion sizes & n.a. \\
Unusual food & n.a. \\
\hline
\end{tabular}

\section{Facilities-Related Attributes}

Mamalis (2009) refers to facilities as an attribute but there was not much detail about the elements of those facilities. Other early authors refer to other aspects such as cleanliness and hygiene. The findings from the study's inter- views identified the following facilities-related attributes: (a) restaurant architecture, (b) cleanliness-hygiene, (c) parking availability, and (d) restaurant tableware.

\section{Service-Related Attributes}

This category was explored in the interviews. A number of authors like Mamalis (2009), Anderson and Mossberg (2004) simply referred to it as service; others are more specific, referring to what may be classified as cues for service. Harrington et al. (2010) for instance mentioned speed, “friendliness," and quality of service. Service quality has so many facets and for that reason the study aimed to shed light on those particular features of the service encounter that appear to be salient features of this group of attributes. A respondent described this difficulty of defining good service, or good quality service in these terms:

Service is another thing ... and then service and our expectations over the years has gradually gone up, so it's more difficult to impress us with a real good service but it's very easy to compromise what we expect. So the danger in service is that it can only have a negative effect and it is extremely difficult for it to have a positive effect. Do you see what I mean? Really good service, you know when you have had it, it's really difficult to describe.

The attributes that correspond to service-related attributes examined in this research are: (a) waiting time to be seated, (b) waiting time to be served food, (c) welcoming/friendliness, (d) attentiveness/interaction, and (e) knowledgeable service.

\section{Place-Related Attributes}

Another set of attributes is related to where the restaurant is located. Place also appears to affect information search as it appears to affect the search between global (i.e., London restaurants) versus local restaurants (close to home). Amongst these attributes the following types were identified: (a) driving distance, (b) convenience for everyone to meet up, (c) vicinity to entertainment area, and (d) public transport available.

\section{Image-Related Attributes}

Aspects such as word-of-mouth or advertising are not often deemed to be attributes of the 
meal experience. Novelty is related to the aspect of unusual food (pursuit for variety), but the term image seems to be worthy of investigation. This study found the following imagerelated attributes: chef reputation, restaurant awards and restaurant branding. This finding is in contrast to Law et al. (2008) study about image-related attributes.

\section{Price-Related Attributes and Perceived Value}

In the literature there are numerous references to price and value, and in many cases there does not seem to be a distinction between the two. Price or value for money as an attribute that could have more or less importance than an attribute like quality of food, for example, have not sufficiently been explored. There is evidence in this study that perceived consumer value is a construct different from price. It was found that a distinction should be made between price-related attributes and perceived consumer value. Price-related attributes are those that directly affect the perceived price, for example, sales incentive programs. These programs may include money off coupons or pricing strategy (for example, having set menus or other tactics that influence perceived price).

\section{Perceived Consumer Value}

Perception of value involves a trade-off between what the customer receives and what they give up; for example, what they pay and the lost opportunity of having spent that time in another place. Indeed, price and value always seem connected to other restaurant attributes (Law et al., 2008). In the context of restaurants, negative consumer perception of value is a mismatch between price and service delivered (Parsa, Self, Njite, \& King, 2005). Hence, the process of perceiving value typically involves a trade-off between perceived benefits and sacrifices; that is, between what the customer receives (e.g., quality, benefits, utilities) and what they give up (e.g., price, opportunity cost, and maintenance cost) to acquire and use a service made a clear connection when defining customer value.

\section{Perceived Consumer Value and Its Relationship with Other Attributes}

It was found in the interviews that perceived consumer value is a construct that encompasses influences from all other attributes. One respondent emphasized the importance of value, and mentioned aspects such as décor, lighting, and menu, with price being just another consideration:

If we have the time we would have a look at the guide if that's an option. But then if we were down the street looking into all the restaurants it would also be lighting and décor of the restaurant and the price and the menu that we would take into consideration. It's not like we would go for the cheapest we would go for value.

Consumers were consciously looking for the best value for the budget available. A respondent explained that this consideration is made together with other restaurant goers in the group:

I don't know because sometimes it depends on how much money you have and budget. And what you want to spend. I have different kinds of friends, different groups and some people can afford it and some can't. If you want to go to a special restaurant because you like it and the quality of the food and can afford that's ok but when you go out with your friends you need to first of all see what friends they are and it also depends on location. Sometimes your friends are students and cannot afford it.

The connection between food quality and value was made clear:

Normally I go for quality as well it doesn't mean it's expensive but it has to be quality at the same time but you normally check. Because the quality of the restaurant equals the 
quality of the food and the money.

Perception of value in the case of drink seems more straightforward. Drink can be a proxy for indicating overall perception of price, thus affecting perceived value. A respondent used the following method: "For me [the decision] sometimes it [depends] will be things like the prices of wine, so you can go to one place and its $£ 18$ a bottle but in others its $£ 25$ for the same thing."

Aspects of image like chef reputation were highlighted by two respondents: “Because if I'm going to pay a lot of money for dinner I want to make sure that it is going to be good and the reputation of the Chef is going to be massively important," and "So if it is a commercial Chef would you pay a lot of money?”

The influence of ambiance on perceived value was outlined by a respondent who gave quite a peculiar example of ambiance over the rest of the experience:

There is a really bad restaurant in Brighton that is renowned for being horrible. You only go for the experience because you have the owner who comes out dancing. And you go and pay 30-40 pounds a head just to laugh at him.

Features of the service also affect perceived value. In the case of waiting time, respondents expect that an expensive restaurant should get their timing right: "So we are talking about meals and restaurants. Two weeks ago I had Sunday roast in this poshy restaurant. We waited for one hour and the meal and the gravy was very salty."

A high level of service is also associated with a higher price: "And simply pouring the wine and really played with it and a really beautiful designed bottle you could see the arm movements and really see he was enjoying it you pay twice as much but you enjoy it."

An association with location was made by two respondents. The first respondent seems to be speaking about a trade-off between a good location and prices that the members of the group can afford:

If you want to go to a special restaurant because you like it and the quality of the food and can afford that's ok but when you go out with your friends you need to first of all see what friends they are and it also depends on location.

Another respondent connected central locations with higher prices:

Oh, I don't mind driving as in Ealing we are not very circulated with restaurants. Having said that, there is a very good fish and chips place that you have been to and Wagamama's that has just opened up which is very good, but really, there is nothing else higher than that in terms of price band. But if you want to eat and make an occasion of it, for example a couple of weeks ago it was my birthday so we went to a deluxe bistro in Baker Street.

In relation to facilities, a respondent linked tableware with formality and higher prices:

Then I go out for a special occasion I expect to have a table cloth on the table and I expect to have proper glasses on the table and I expect to be treated and pampered that's why we save money for the special occasion we pay lots of money and we want to be served properly and like we did for Peter's birthday we went out it was very nice.

Another respondent highlighted the same issue with the reverse argument:

I don't mind going to some nice place to have a glass of wine in a nice normal glass.

When you're paying $£ 15, £ 20$, or $£ 25$ for a meal and you know you just want to have a full tummy and that's all but for a special occasion that's what I expect.

The link between price-related attributes like pricing strategy and perceived value is almost 
obvious. A respondent put it like this:

A grilled sea bass you would expect that to come with something and pay for a side salad. .. perhaps but it they have itemized everything else because most main courses are about $20 £ i s h$ a bit less, you would expect that to be included. So the value for money as far as I am concerned would be to have an inclusive menu choice.

It is important to emphasize that respondents willingly referred to these associations between perceived consumer value and attributes. Also it seems that price-related attributes may be associated with perceived value: "It actually doesn't attract me to go into a restaurant if they did in fact have promotion.” Another stressed that promotion "cheapens the offer," implying something is wrong with that place if they need to have promotions: "Then they should rely on word of mouth. I would never go to a place for a promotion. It smells cheap. It's too demeaning."

On the other hand, while sometimes consumers refer to value and overall perceived value, others refer to price. For instance, the need for promotions (price-related attributes) may be dependent on other attributes. For example, a badly located restaurant could compensate for that with promotions (price-related attributes). A model that makes causal assertions is proposed. These imply that attributes affect perceived consumer value and price-related attributes and that there is also a relationship between price-related values and perceived consumer values.

\section{Conclusions and Implications}

The contribution of this research is the presentation and discussion of a new classification of restaurant attributes. This classification has the following attributes: food and drink-related attributes, ambiance and atmosphere-related attributes, facilities-related attributes, price-related attributes, service-related attributes, location and place-related attributes, and image-related attributes. This study has also revealed that perceived value is interrelated to the other restaurant attributes. This led to suggesting a model that shows the relationships between attributes and between attributes and perceived consumer value (Figure 1).

The proposed model does not approach value for money or perceived price as just another attribute that could be ranked in importance (as in some models like the original meal experience model). The focus group interviews have revealed some relationships between that perceived value and other restaurant attributes and how attributes affect price-related attributes as well. Some respondents even use rules of thumb related to price, for example comparing prices of bottles of wine and then comparing the other attributes and selecting the alternative with the highest value. This confirms Marney's (2001) assertions on the importance of perceived value as a good predictor of customer behavior. It has been found that consumers elaborate on several attributes linking them with value for money, for example portion sizes. This confirms the assertions of Hsee, Loewenstein, Blount, and 


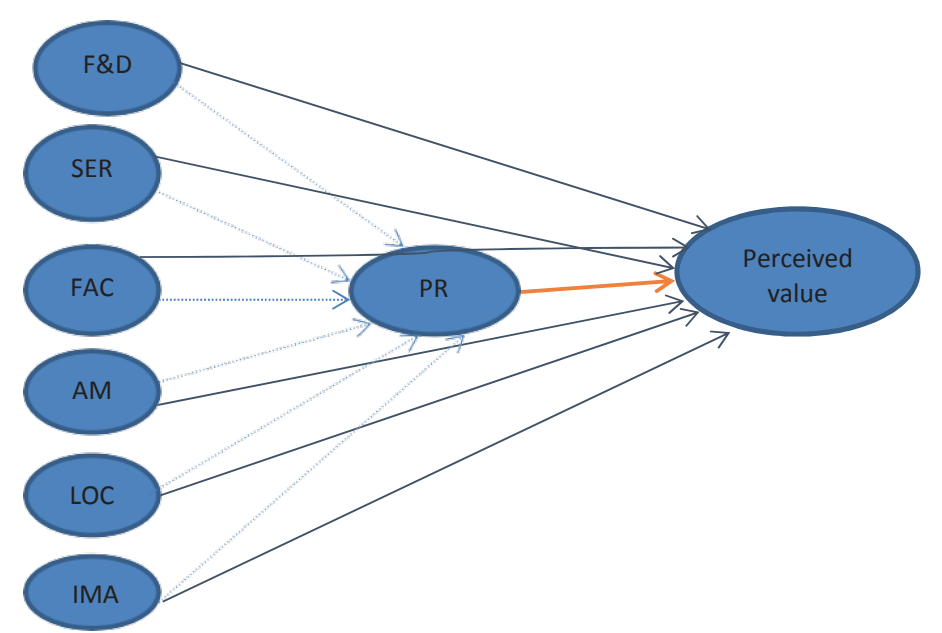

Figure 2. Path diagram for proposed model.

Bazerman (1999)about the pursuit of a better deal as a key heuristic. The model also suggests that the price charged relates to other attributes.

The study acknowledges that it excluded fast-food restaurants and nonleisure eating out. It was anticipated that more attributes would have been elicited from a full service than if restaurants with less level of service would have been considered. Also, it would have been beneficial to conduct interviews in other geographical areas so as to elicit attributes that might have been relevant in other contexts. All the same, this is considered to be a first step towards a new model for restaurant attributes that we suggest must be statistically tested. The pro- posed model in Figure 1 shows multiple relationships for which dependence relationships need to be established. This can be done with structural equation modeling, for which a pictorial representation using a path diagram is required. The path diagram is depicted in Figure 2.

The different categories represent dimensions or factors; then there are particular indicators of those dimensions. Hence, for reasons of space these dimensions and the subattributes that they represent will be presented in a follow-up article.

\section{ORCID}

Pedro Longart @ http://orcid.org/0000-0001-8595-5778

\section{References}

Andaleeb, S. S., \& Conway, C. (2006). Customer satisfaction in the restaurant industry: An examination of the transaction-specific model. Journal of Services Marketing, 20(1), 3-11. doi:10.1108/08876040610646536

Anderson, S. P., Goeree, J. K., \& Ramer, R. (1997). Location, location, location. Journal of Economic Theory, 77(1), 102-127. doi:10.1006/jeth.1997.2323

Anderson, T. D., \& Mossberg, L. (2004). The dining experience: Do restaurants satisfy customers' needs? Food Service Technology, 4(4), 171-177. doi:10.1111/j.14715740.2004.00105.x

Arora, R., \& Singer, J. (2006). Customer satisfaction and value as drivers of business success for fine dining restaurants. Services Marketing Quarterly, 28(1), 89-102. doi:10.1300/ J396v28n01_05

Auty, S. (1992). Consumer choice and segmentation in the restaurant industry. The Service Industries Journal, 12(3), 324-339. doi:10.1080/02642069200000042

Babin, B. J., Lee, Y.-K., Eun, J.-K., \& Griffin, M. (2005). Modelling consumer satisfaction 
and word-of-mouth patronage in Korea. The Journal of Services Marketing, 19(3), 133138. doi:10.1108/08876040510596803

Barber, N., \& Scarcelli, J. M. (2009). Clean restrooms: How important re they to restaurant consumers? Journal of Foodservice, 20(6), 309-320. doi:10.1111/j.1748-

0159.2009.00155.x Barrows, C., \& Vieira, E. T. (2013). Recommendations for the development of a new operational classification system for the foodservice industry. Journal of Hospitality \& Tourism Research, 37(3), 349-376. doi:10.1177/1096348012436375.

Bazeley, P., \& Jackson, K. (2013). Qualitative data analysis with Nvivo (2nd ed.). London, England: Sage.

Bolton, R. N., \& Drew, J. H. (1991). A multistage model of customers' assessments of service quality and value. Journal of Consumer Research, 17(4), 375-384. doi:10.1086/jcr.1991.17. issue-4

Boyatzis, R. E. (1998). Transforming qualitative information: Thematic analysis and code development. Thousand Oaks, CA: Sage.

Braun, V., \& Clarke, V. (2006). Using thematic analysis in psychology. Qualitative Research in Psychology, 3(2), 77-101. doi:10.1191/1478088706qp063oa

Cadotte, E. R., \& Turgeon, N. (1988). Key factors in guest satisfaction. Cornell Hotel and Restaurant Administration Quarterly, 28(4), 283-320. doi:10.1177/001088048802800415 Campbell-Smith, G. (1967). The marketing of the meal experience. London, England: University of Surrey Press.

Cannarozzo-Tinoco, M. A., \& Duarte-Ribeiro, L. (2012). Main attributes of quality and price perception for a la carte restaurants. Management, 2(2), 40-48. doi:10.5923/j. mm.20120202.02

Castro, C. B., Armario, M., \& Ruiz, M. (2007). The influence of market heterogeneity on the relationship between a destination's image and tourists' future behaviour. Tourism Management, 28(1), 175-187. doi:10.1016/j.tourman.2005.11.013

Chang, K.-C. (2013). How reputation creates loyalty in the restaurant sector. International Journal of Contemporary Hospitality Management, 25(4), 536-557. doi:10.1108/ 09596111311322916

Chen, C., \& Tsai, D. C. (2007). How destination image and evaluative factors affect behavioural intentions? Tourism Management, 28(4), 1115-1122. doi:10.1016/j. tourman.2006.07.007

Clark, M. A., \& Wood, R. C. (1998). Consumer loyalty in the restaurant industry-a preliminary exploration of the issues. International Journal of Contemporary Hospitality Management, 10(4), 139-144. doi:10.1108/09596119810222104

Cousins, J., Foskett, D., \& Gillespie, C. (2002). Food and beverage management (2nd ed.). Harlow, England: Prentice Hall.

Denove, C., \& Power, J. D. (2006). Satisfaction. New York, NY: Portfolio.

Devine, I., \& Halpern, P. (2001). Implicit claims: The role of corporate reputation in value creation. Corporate Reputation Review, 4(1), 42-49. doi:10.1057/palgrave.crr.1540131

Dhurup, M., Mafini, C., \& Malan, J. (2013). Consumer responses to salient image attributes in restaurant selection in Southern Gauteng, South Africa. Mediterranean Journal of Social Sciences, 4(3), 283-294.

Di-Cicco-Bloom, B., \& Crabtree, B. F. (2006). The qualitative research interview. Medical Education, 40, 314-321. doi:10.1111/med.2006.40.issue-4

Dulen, J. (1999). Quality control. Restaurant \& Institutions, 109(5), 38-52.

Dutta, K., Parsa, H. G., Parsa, R. A., \& Bujisic, M. (2014). Change in consumer patronage and willingness to pay at different levels of service attributes in restaurants: A study in India. Journal of Quality Assurance in Hospitality \& Tourism, 15(2), 149-174. 
doi:10.1080/ 1528008X.2014.889533

Dye, J. F., Schatz, I. M., Rosenberg, B. A., \& Coleman, S. T. (2000). Constant comparison method: A kaleidoscope of data. The Qualitative Report, 4(1/2), 1-9.

Finkelstein, J. (1989). Dining out: A sociology of good manners. New York, NY: University of New York Press.

Gallarza, M. G., Saura, I. G., \& Garcia, H. C. (2002). Destination image towards a conceptual framework. Annals of Tourism Research, 29(1), 56-78. doi:10.1016/S01607383(01)00031-7

Gardial, S. F., Clemons, D. S., Woodruff, R. B., Schumann, D. W., \& Burns, M. J. (1994). Comparing consumers' recall of pre-purchase and post-purchase product evaluation experiences. Journal of Consumer Research, 548-560. doi:10.1086/209369

Gladwell, M. (2000). The tipping point. London, England: Abacus.

Guest, G., MacQueen, K. M., \& Namey, E. E. (2012). Applied thematic analysis. London, England: Sage.

Gupta, S., McLaughlin, E., \& Gomez, M. (2007). Guest satisfaction and restaurant performance. Cornell Hotel and Restaurant Administration Quarterly, 48(3), 284-298. doi:10.1177/0010880407301735

Gustaffson, I. B., Oström, A., Mossberg, L., \& Johansson, J. (2006). The Five Aspects Meal Model: A tool for developing food services in restaurants. Journal of Food Service, 17(2), 84-93.

Ha, J., \& Jang, S. (2013). Attributes, consequences, and consumer values: A means-end chain approach across restaurant segments. International Journal of Contemporary Hospitality Management, 25(3), 383-409. doi:10.1108/09596111311311035

Haghighi, M., Dorosti, A., Rahnama, A., \& Hoseinpour, A. (2012). Evaluation of factors affecting customer loyalty in the restaurant industry. African Journal of Business Management, 6(14), 5039-5046.

Hair, J. F., Anderson, R. E., Babin, B. J., \& Black, W. C. (2010). Multivariate data analysis: A global perspective (Vol. 7). Upper Saddle River, NJ: Pearson.

Hanefors, M., \& Mossberg, L. (2003). Searching for the extraordinary meal experience. Journal of Business and Management, 9(3), 249-270.

Hansen, K. V., Jensen, O., \& Gustaffson, I. B. (2005). The meal experiences of a la carte restaurant customers. Scandinavian Journal of Hospitality and Tourism, 5(2), 135-151. doi:10.1080/15022250510014417

Harrington, R. J., Ottenbacher, M. C., Staggs, A., \& Allen-Powell, F. (2011). Generation Y consumers: Key restaurant attributes affecting positive and negative experiences. Journal of Hospitality \& Tourism Research, 20(10), 1-19.

Harrington, R. J., Ottenbacher, M. C., \& Way, K. A. (2010, July 31). QSR choice: Key restaurant attributes and the role of gender, age and dining frequencyPresented at International CHRIE Conference Retrieved from http://scholarworks.umass.edu/refereed/ CHRIE_2010/Saturday/14

Hartman, K. B., \& Spiro, R. (2005). Recapturing store image in customer based store equity: A construct conceptualisation. Journal of Business Research, 58(8), 1112-1120. doi:10.1016/ j.jbusres.2004.01.008

Hsee, C. K., Loewenstein, G. F., Blount, S., \& Bazerman, M. H. (1999). Preference reversals between joint and separate evaluations of options: A review and theoretical analysis. Psychological Bulletin, 125(5), 576. doi:10.1037/0033-2909.125.5.576

Hwang, J., \& Ok, C. (2013). The antecedents and consequence of consumer attitudes toward restaurant brands: A comparative study between casual and fine dining restaurants. International Journal of Hospitality Management, 32, 121-131. doi:10.1016/j. ijhm.2012.05.002 
Jensen, Ø., \& Hansen, K. V. (2007). Consumer values among restaurant customers. International Journal of Hospitality Management, 26(3), 603-622. doi:10.1016/j. ijhm.2006.05.004

Josiam, B. M., Sohail, S. M., \& Monteiro, P. A. (2007). Curry cuisine: Perceptions of Indian restaurants in Malaysia. Tourismos: An International Multidisciplinary Journal of Tourism, 2(2), 25-37.

June, L. P., \& Smith, S. L. J. (1987). Service attributes and situational effects on customer preferences for restaurant dining. Journal of Travel Research, 26(2), 20-27. doi:10.1177/ 004728758702600205

Jung, J. M., Sydnor, S., Lee, S. K., \& Almanza, B. (2015). A conflict of choice: How consumers choose where to go for dinner. International Journal of Hospitality Management, 45, 88-98. doi:10.1016/j.ijhm.2014.11.007

Keyt, J. C., Yavas, U., \& Riecken, G. (1994). Importance-performance analysis: A case study in restaurant positioning. International Journal of Retail \& Distribution Management, 22(5), 35-40. doi:10.1108/09590559410067325

Kim, W. G., Lee, Y. K., \& Yoo, Y. J. (2006). Predictors of relationship quality and relationship outcomes in luxury restaurants. Journal of Hospitality \& Tourism Research, 30(2), 143-169. doi:10.1177/1096348005285086

Kivela, J. J. (1997). Restaurant marketing: Selection and segmentation in Hong Kong. International Journal of Contemporary Hospitality Management, 9(3), 116-123. doi:10.1108/09596119710164650

Koo, L. C., Tao, F. K. C., \& Yeung, J. H. C. (1999). Preferential segmentation of restaurant attributes through conjoint analysis. International Journal of Contemporary Hospitality Management, 11(5), 242-250. doi:10.1108/09596119910272784

Kotler, P. (1973/1974). Atmospherics as a marketing tool. Journal of Retailing, 49(4), $48-64$. Law, R., To, T., \& Goh, C. (2008). How do Mainland Chinese travellers choose restaurants in Hong Kong? An exploratory study of individual visit scheme travellers and packaged travellers. International Journal of Hospitality Management, 27(3), 346-354. doi:10.1016/j.ijhm.2007.10.004

Lewis, R. C. (1980). Benefit segmentation: Restaurant advertising that works. Cornell Hotel and Restaurant Administration Quarterly, 21(6), 6-12.

doi:10.1177/001088048002100303 Lewis, R. C. (1981). Restaurant advertising: Appeals and consumers' intentions. Journal of Advertising Research, 21(5), 69-74.

Longart, P. (2010). What drives word of mouth in restaurants? International Journal of Contemporary Hospitality Management, 22(1), 121-128. doi:10.1108/09596111011013516

Lu, A. C. C., Gursoy, D., \& Lu, C. Y. (2015). Authenticity perceptions, brand equity and brand choice intention: The case of ethnic restaurants. International Journal of Hospitality Management, 50, 36-45. doi:10.1016/j.ijhm.2015.07.008

Macht, M., Meininger, J., \& Roth, J. (2005). The pleasures of eating: A qualitative analysis. Journal of Happiness Studies, 6(2), 137-160. doi:10.1007/s10902-005-0287-x

Mamalis, S. (2009). Critical success factors of the foodservice industry. Journal of International Food \& Agribusiness Marketing, 21(2/3), 191-206. doi:10.1080/ 08974430802589709

Marković, S., Raspor, S., \& Šegarić, K. (2010). Does restaurant performance meet customers' expectations? An assessment of restaurant service quality using a modified dineserv approach. Tourism and Hospitality Management, 16(2), 181-195.

Marney, J. (2001, October 9). Bringing consumers back for more. Marketing Magazine, 106 (36), 33.

Mehta, S. S., \& Maniam, B. (2002). Marketing determinants of customers' attitudes towards 
selecting a restaurant. Academy of Marketing Studies Journal, 6(1), 27-44.

Milliman, R. E. (1986). The influence of background music on the behaviour of restaurant patrons. Journal of Consumer Research, 13(2), 286-289. doi:10.1086/209068

Morgan, M., Watson, P., \& Hemmington, N. (2008). Drama in the dining room: Theatrical experiences on the Foodservice encounter. Journal of Foodservice, 19(2), 111-118. doi:10.1111/j.1745-4506.2008.00090.x

Namkung, Y., \& Jang, S. S. (2008). Are highly satisfied restaurant customers really different? A quality perception perspective. International Journal of Contemporary Hospitality Management, 20(2), 142-155. doi:10.1108/09596110810852131

Narine, T., \& Badrine, N. (2007). Influential factors affecting food choices of consumers when eating outside the household in Trinidad, West Indies. Journal of Food Products Marketing, 13(1), 19-29. doi:10.1300/J038v13n01_02

Nitiwanakul, W. (2014). A comparative study of customer perceived value as a driver for fine dining restaurant selection: A case of Thai consumers and expatriates. AU Journal of Management, 12(1), 1-13.

Pantelidis, I. S. (2010). Electronic meal experience: A content analysis of online restaurant comments. Cornell Hospitality Quarterly, 51(4), 483-491. doi:10.1177/1938965510378574

Parasuraman, A., Zeithaml, V. A., \& Berry, L. L. (1988). SERVQUAL: A multiple-item scale for measuring consumer perceptions of service quality. Journal of Retailing, 64(1), 12-40.

Park, M. H., Hong, J. H., \& Cho, S. B. (2007). Location-based recommendation system using Bayesian user's preference model in mobile devices. In Indulska, J., Ma, J., Yang, L.T., Ungerer, T., \& Cao, J. (Eds.),Ubiquitous intelligence and computing (pp. 1130-1139). Berlin, Germany: Springer.

Parsa, H. G., Self, J. T., Njite, D., \& King, T. (2005). Why restaurants fail? Cornell Hotel and Restaurant Administration Quarterly, 46(3), 304-323. doi:10.1177/0010880405275598

Pedraja, M., \& Yague, M. J. (2004). Perceived quality and price: Their impact on the satisfaction of restaurant customers. International Journal of Contemporary Hospitality Management, 16(6), 373-379.

Ponnam, A., \& Balaji, M. S. (2014). Matching visitation-motives and restaurant attributes in casual dining restaurants. International Journal of Hospitality Management, 37, 47-57. doi:10.1016/j.ijhm.2013.10.004

Reynolds, T. J., \& Gutman, J. (1988). Laddering theory, method, analysis, and interpretation. Journal of Advertising Research, 28(1), 11-31.

Ribeiro-Soriano, D. (2002). Customers' expectations factors in restaurants: The situation in Spain. International Journal of Quality \& Reliability Management, 19(8/9), 1055-1067. doi:10.1108/02656710210438122

Ritchie, J., Lewis, J., McNaughton Nicholls, C., \& Ormston, R. (2014). Qualitative research practice (2nd ed.). London, England: Sage.

Ryu, K., Heesup, H., \& Tae-Hee, K. (2008). The relationships among overall quick-casual restaurant image, perceived value, customer satisfaction, and behavioural intentions. International Journal of Hospitality Management, 27(3), 459-469. doi:10.1016/j. ijhm.2007.11.001

Ryu, K., Lee, H.-R., \& Kim, W. G. (2012). The influence of the quality of the physical environment, food, and service on restaurant image, customer perceived value, customer satisfaction, and behavioural intentions. International Journal of Contemporary Hospitality Management, 24(2), 200-223. doi:10.1108/09596111211206141

Stevens, P., Knutson, B., \& Patton, M. (1995). Dineserv: A tool for measuring service quality in restaurants. Cornell Hotel and Restaurant Administration Quarterly, 36(2), 56-60. doi:10.1177/001088049503600226 
Sulek, J. M., \& Hensley, R. L. (2004). The relative importance of food, atmosphere, and fairness of wait the case of a full-service restaurant. Cornell Hotel and Restaurant Administration Quarterly, 45(3), 235-247. doi:10.1177/0010880404265345

Susskind, A. M., \& Chan, E. K. (2000). How restaurant features affect check averages: A study of the Toronto restaurant market. Cornell Hotel and Restaurant Administration Quarterly, 41(6), 56-63.

Sweeney, J. C., Soutar, G. N., \& Johnson, L. W. (1999). The role of perceived risk in the quality-value relationship: A study in a retail environment. Journal of Retailing, 75(1), 77105. doi:10.1016/S0022-4359(99)80005-0

Tasci, A. D., Gartner, W. C., \& Cavusgil, S. T. (2007). Conceptualization and operationalization of destination image. Journal of Hospitality \& Tourism Research, 31(2), 194-223. doi:10.1177/1096348006297290

Teas, R. K., \& Agarwal, S. (2000). The effects of extrinsic product cues on consumers' perceptions of quality, sacrifice, and value. Journal of the Academy of Marketing Science, 28(2), 278-290. doi:10.1177/0092070300282008

Titz, K. (2004). The anatomy of restaurant reviews. International Journal of Hospitality and Tourism Administration, 5(1), 49-66. doi:10.1300/J149v05n01_03

Tse, A. C. B. (2001). How much more are consumers willing to pay for a higher level of service? A preliminary survey. Journal of Services Marketing, 15(1), 11-17. doi:10.1108/ 08876040110381328

Tzeng, G. H., Teng, M. H., Chen, J. J., \& Opricovic, S. (2002). Multi-criteria selection for a restaurant location in Taipei. International Journal of Hospitality Management, 21(2), 171- 187. doi:10.1016/S0278-4319(02)00005-1

Upadhyay, Y., Singh, S. K., \& Thomas, G. (2007). Do people differ in their preferences regarding restaurants? An exploratory study. Vision: The Journal of Business Perspective, 11 (2), 7-22.

Vilnai-Yavetz, I., \& Gilboa, S. (2010). The effect of servicescape cleanliness on customer reactions. Services Marketing Quarterly, 31(2), 213-234. doi:10.1080/15332961003604386

Wakefield, K. L., \& Blodgett, J. G. (1994). The importance of servicescapes in leisure service settings. Journal of Services Marketing, 8(3), 66-76. doi:10.1108/08876049410065624

Walczak, D. (1997). The sanitation imperative: Keep people from getting sick in your restaurant. Cornell Hotel and Restaurant Administration Quarterly, 38(2), 68-73.

Wall, E. A., \& Berry, L. L. (2007). The combined effects of the physical environment and employee behaviour on customer perception of restaurant service quality. Cornell Hotel and Restaurant Administration Quarterly, 48(1), 59-69. doi:10.1177/0010880406297246

Woodruff, R. B. (1997). Customer value: The next source for competitive advantage. Journal of the Academy of Marketing Science, 25(2), 139-153. doi:10.1007/BF02894350

Yüksel, A., \& Yüksel, F. (2003). Measurement of tourist satisfaction with restaurant services: A segment-based approach. Journal of Vacation Marketing, 9(1), 52-68. doi:10.1177/ 135676670200900104

Yun, Z., \& Good, L. K. (2007). Developing customer loyalty from e-tail store image attributes. Management and Service Quality, 17(1), 4-22. doi:10.1108/09604520710720647

Zeithaml, V. A. (1988). Consumer perceptions of price, quality, and value: A means-end model and synthesis of evidence. The Journal of Marketing, 52(3), 2-22. doi:10.2307/ 1251446 